\title{
Concomitant Laparoendoscopic Single-Site Surgery for Vesicolithotomy and Finger-Assisted Single-Port Transvesical Enucleation of the Prostate
}

\author{
Joo Yong Lee, Dong Hyuk Kang, Jae Hoon Chung, Jung Ki Jo, Seung Wook Lee \\ Department of Urology, Hanyang University College of Medicine, Seoul, Korea
}

\begin{abstract}
Transurethral resection of the prostate is the most common surgery for benign prostatic hyperplasia. However, it doesn't work best for men with very large prostate and bladder stones. Herein we report our initial experience with concomitant laparoendoscopic single-site surgery and finger-assisted single-port transvesical enucleation of the prostate for the treatment of the condition.
\end{abstract}

Keywords: Urinary bladder calculi; Prostatic hyperplasia; Laparoscopy; Minimally invasive surgical procedures

Open prostatectomy has been believed to be more effective than transurethral resection of the prostate (TURP) in the case of large benign prostatic hyperplasia $(\mathrm{BPH})$ with a prostatic volume of $80 \mathrm{~mL}$ or more [1]. The use of laparoendoscopic singlesite surgery (LESS) to treat benign diseases in urology has recently been increasing [2]. In particular, LESS has been reported to have advantages of better cosmesis, shorter hospitalization, and higher satisfaction than open or conventional laparoscopic surgery [3]. In particular, LESS for BPH treatment was introduced and is referred to as single-port transvesical enucleation of the prostate (STEP) [4]. Two studies with a large number of cases have already reported $[5,6]$. We report herein a case of concomitant LESS for vesicolithotomy (LESSV) and fingerassisted STEP (F-STEP) with the use of a homemade singleport device to treat bladder stones and large $\mathrm{BPH}$. We also present a brief review of the literature.

\section{CASE REPORT}

A 78-year-old man visited our emergency room complaining of acute urinary retention. He presented with a 10-year history of voiding difficulty. Before this presentation, a digital rectal examination revealed bilateral enlargement of the prostatic lobes. Under a clinical diagnosis of BPH, he was administered tamsulosin $0.2 \mathrm{mg}$ once with the insertion of a urethral Foley catheter. Transrectal ultrasonography revealed that the volume of the prostate was approximately $136 \mathrm{~mL}$ (Fig. 1A, B). His prostatespecific antigen level was $2.12 \mathrm{ng} / \mathrm{mL}$. Two weeks later, a pressure flow study (PFS) was performed to evaluate his voiding symptoms and showed an obstructive pattern and normal detrusor function according to the International Continence Society and Schäffer nomogram (Fig. 1C). His maximal urine flow rate (Qmax) was $9 \mathrm{~mL} / \mathrm{sec}$ on the PFS. Simple X-ray and computed tomography (CT) scan suggested the presence of several bladder stones. Other solid organs were all within normal limits on the CT scan. We decided to perform concomitant LESSV and STEP under a diagnosis of bladder stones and BPH. Informed consent was obtained after a complete description of the LESS with the use of a homemade single-port device.

With the patient under general anesthesia, a urethral Foley catheter was inserted in a supine low lithotomy position. A homemade single-port device was prepared as described in a
Corresponding author: Seung Wook Lee

Department of Urology, Hanyang University Guri Hospital, Hanyang University

College of Medicine, 249-1 Gyomun-dong, Guri 471-701, Korea

Tel: +82-31-560-2374 / Fax: +82-31-560-2372

E-mail: swleepark@hanyang.ac.kr

Submitted: October 24, 2011 / Accepted after revision: December 14, 2011
This is an Open Access article distributed under the terms of the Creative Commons Attribution Non-Commercial License (http://creativecommons.org/licenses/by-nc/3.0/) which permits unrestricted non-commercial use, distribution, and reproduction in any medium, provided the original work is properly cited. 

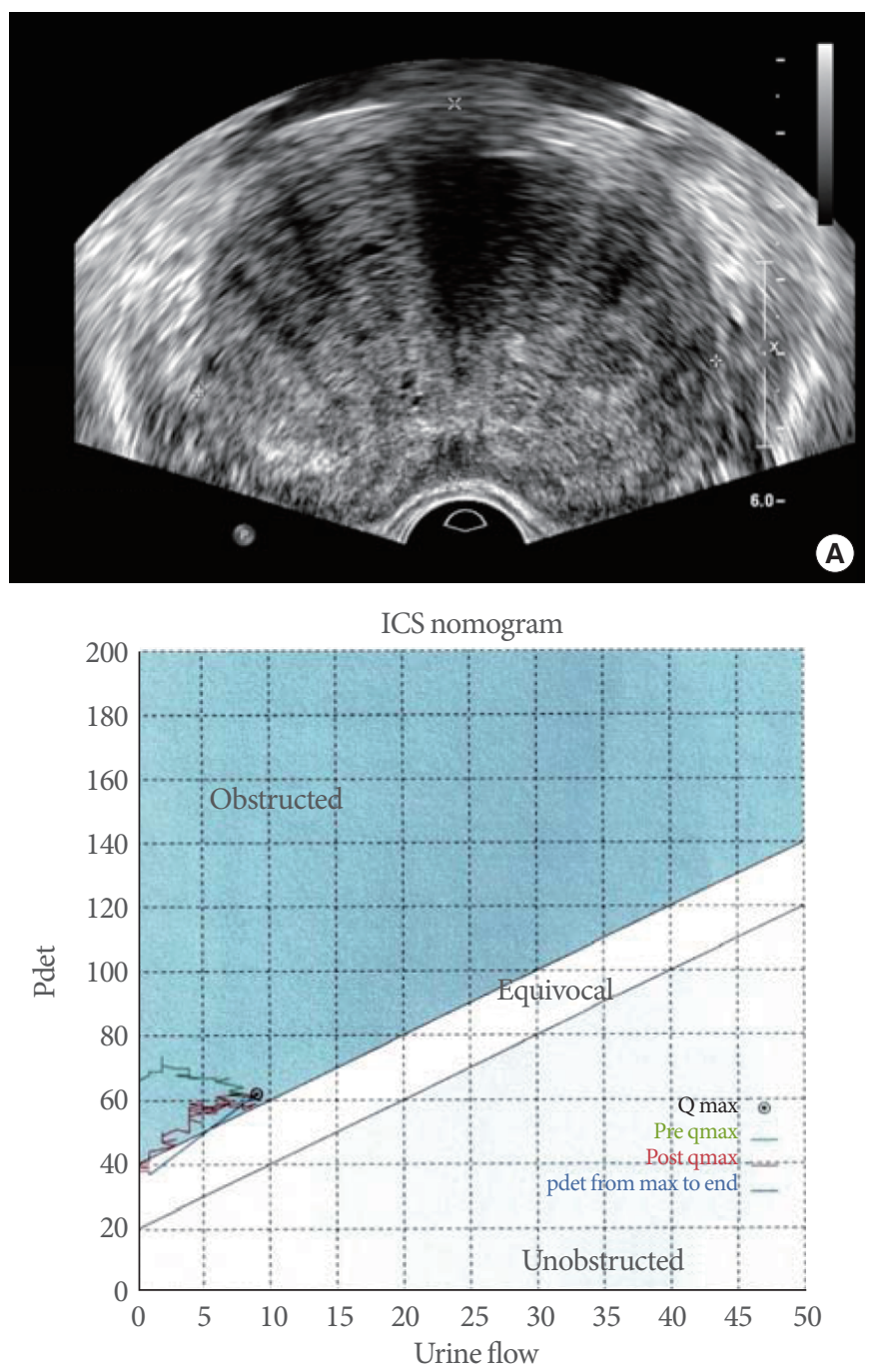

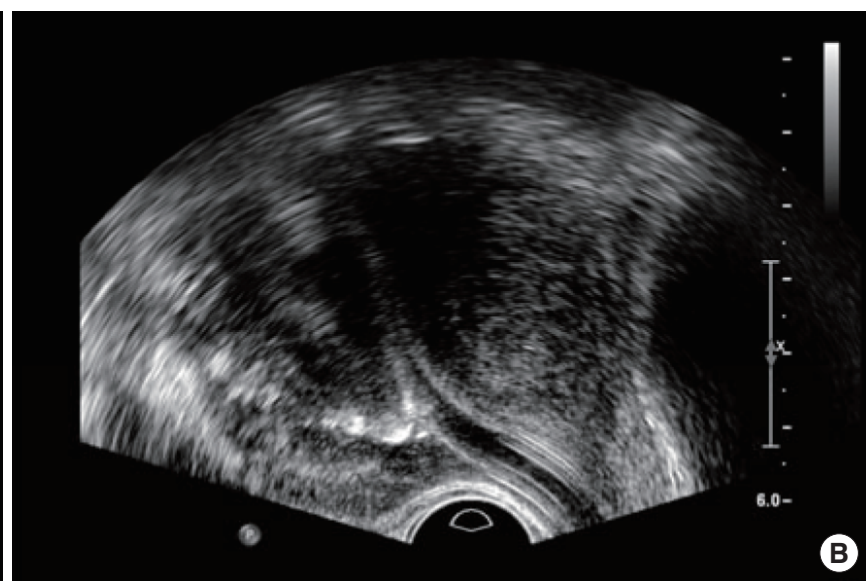

Schäfer nomogram

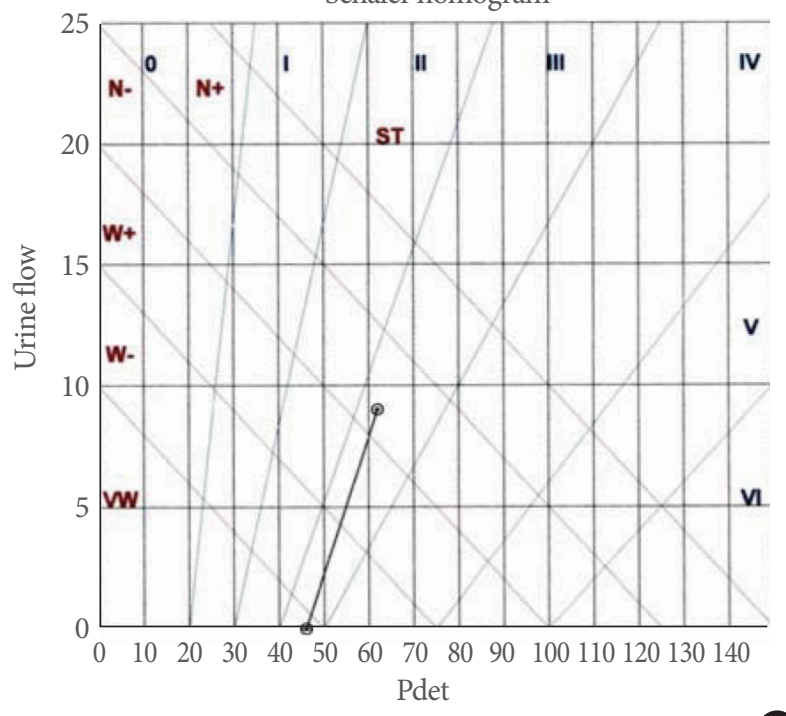

Urethra; $0=$ normal; $\mathrm{I}=$ mild $\rightarrow \mathrm{VI}=$ severe obs.

Detrusor; Very Weak-/Weak+/Normal-/Normal+/STrong

Fig. 1. (A, B) Transrectal ultrasonography revealed that the volume of the prostate was approximately $136 \mathrm{~mL}$. (C) Pressure flow study revealed an obstructive pattern and normal detrusor function according to the International Continence Society (ICS) and Schäffer nomogram. Qmax, maximal urine flow rate; pdet, detrusor pressure.

previous report [7]. A midline incision of approximately $3 \mathrm{~cm}$ was made at the level of three fingerbreadths above the symphysis pubis, followed by a dissection to reach the bladder. The anterior wall of the bladder was then incised at approximately 2 $\mathrm{cm}$ to minimize the bladder wall and port-device. Pneumovesicum was formed while maintaining $12 \mathrm{~cm} \mathrm{H}_{2} \mathrm{O}$ pressure. Using a 10-mm rigid laparoscope (ConMed Linvatec, Largo, FL, USA), the prostatic adenoma, urethral Foley catheter, and bilateral ureteral orifices were checked (Fig. 2A, B). Urinary drainage was halted to prevent gas leakage, and the urethral catheter tip was then moved to the bladder neck. Using rigid instruments, the bladder stones were grasped and extracted through a hole in another finger of the glove. After removal of the bladder stones, a dissection was made starting from the right prostatovesical junction using a rigid laparoscopic dissector and an EnSeal Trio Tissue Sealing Device (Ethicon Endo-Surgery Inc., Cincinnati, OH, USA) (Fig. 2D-G). Air ventilation was continuously maintained to minimize vesical neuromuscular trauma due to visual field securing and pneumovesicum. After sufficient dissection of the huge adenoma, the port-device was removed. Using Ellis forceps, the huge adenoma was pulled outward and the index finger was inserted into the dissection plane as described in a previous report [6]. Continuous irrigation was maintained following extraction of the adenoma. The suprapu- 

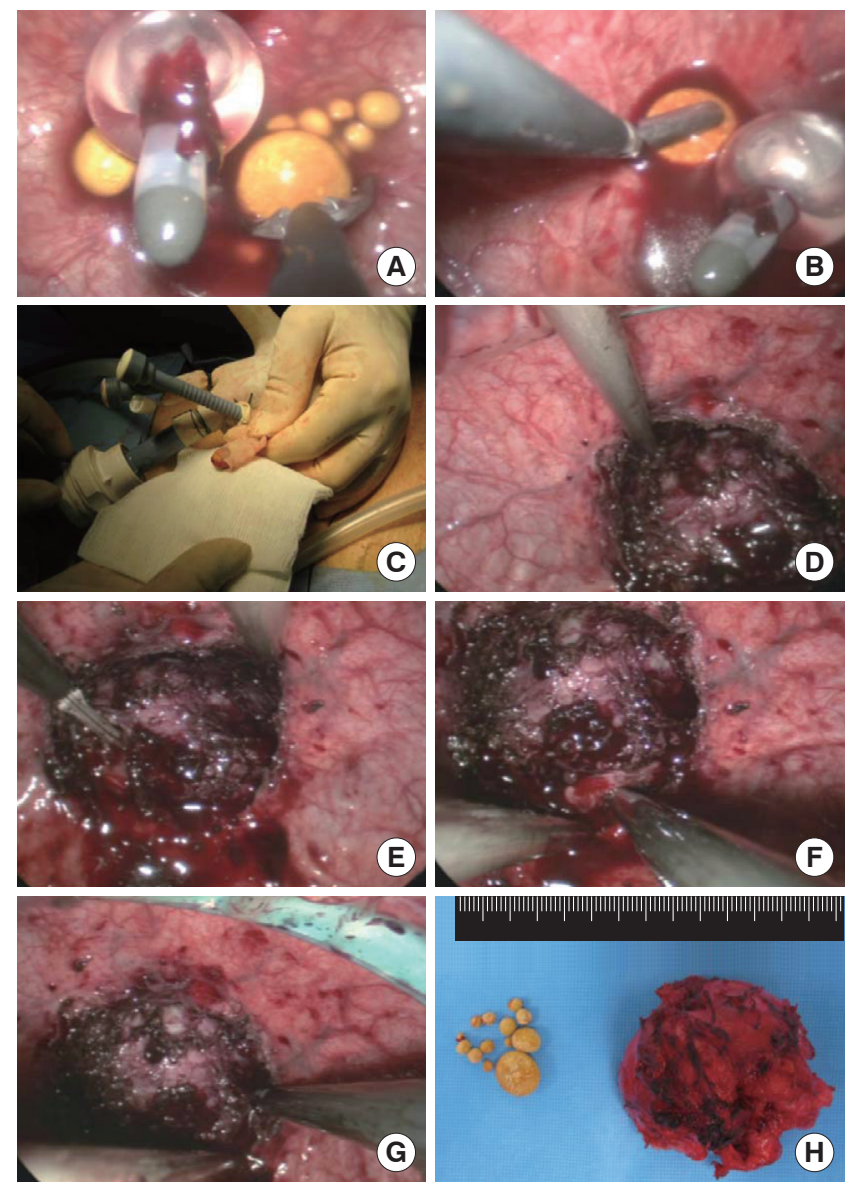

Fig. 2. (A-C) Using rigid instruments, bladder stones were grasped and extracted through a hole in another finger of the glove. (D-G) A dissection was made starting from the prostatovesical junction using a rigid laparoscopic dissector and EnSeal Trio Tissue Sealing Device. (H) The resected prostate weight was approximately $118 \mathrm{~g}$.

bic catheter was used to make up for the obstruction of the urethral catheter. The bladder was sutured with 3 layers, and the skin was approximated by using a skin stapler (3M Precise Skin Stapler, 3M Co., Preston, MN, USA). The suprapubic and urethral catheter were removed on the 7th and 8th postoperative day, respectively. Two weeks later, the patient's postoperative Qmax was $48 \mathrm{~mL} / \mathrm{sec}$. Fig. $2 \mathrm{H}$ shows the extracted bladder stones and prostatic adenoma. Pathological results revealed nodular hyperplasia.

\section{DISCUSSION}

Desai et al. [8] and Sotelo et al. [9] first reported STEP for large BPH using an R-port (Advanced Surgical Concepts, Wicklow,
Ireland) between 2008 and 2009. The two groups of Desai and Sotelo jointly reported 34 cases of STEP including a case of RLESS in 2010 [5]. In their study, the authors conducted the enucleation by using electrocautery and ultrasonic shears under laparoscopic video assistance. The small intravesical portion was enucleated by using fingers in 19 cases. Interestingly, Oh and Park [6] reported 32 cases of F-STEP in the treatment of a huge prostate following Desai et al. In their study, they reported a new enucleation method using fingers and excellent outcomes. After the prostatic capsule was dissected with the use of articulating instruments, traction suturing was performed on the prostatic adenoma. The adenoma was enucleated by using the index finger after removing the homemade single-port device. In our case, we used the same method to remove the prostatic adenoma, because the prostatic adenoma was too large to remove with the use of laparoscopic instruments.

In fact, use of LESS for the primary treatment of urological cancers might be limited because of issues such as the extraction method of the specimen and maintaining oncologic principles [10]. Patient selection with LESS is more exact than with conventional laparoscopy [3]. The ideal indications for LESS may be pediatric urologic diseases and benign, non-life-threatening diseases [11]. Recently, Kaouk et al. [12] reported a worldwide multi-institutional analysis of 1,076 cases of LESS in urology. In their study, malignant disease including renal tumor, adrenal tumor, prostate cancer, and bladder cancer made up approximately $46.6 \%$ of the sample. More than half of the cases were benign disease, for which LESS was performed. In benign urologic disease, there were 42 cases (3.9\%) of LESS for BPH including STEP.

To the best of our knowledge, concomitant LESSV and FSTEP have not been reported in previous studies. STEP was estimated to be a very difficult procedure according to Autorino et al. [13]. However, it may be more advantageous for surgeons with experience in LESS or conventional laparoscopy, but may show a steep learning curve as shown for Holmium laser enucleation of the prostate (HoLEP) or an even steeper learning curve in surgeons without experience in LESS or conventional laparoscopy. Although STEP has better cosmesis than open surgery, it may require a suprapubic catheter and may have an external wound compared to TURP or HoLEP. However, STEP or F-STEP might be a viable treatment option in patients with huge prostate of more than $80 \mathrm{~mL}$.

In our case, the concomitant LESSV and F-STEP has some advantages, as follows: urethra and bladder neck injuries may 
occur due to the long-time use of a rigid resectoscope, but they can be prevented in concomitant LESSV and F-STEP. Suturing is also a very difficult technique in LESS [2]. Meanwhile, no suturing with laparoscopic instruments is required in F-STEP as compared with pyelolithotomy or ureterolithotomy. For a large bladder stone, another lithotripter might not be required in LESSV. In addition, the single incision in the concomitant LESSV and F-STEP without the need for a position change is an important advantage. Our case suggests that concomitant LESSV and F-STEP can be used as an alternative technique in the treatment of huge BPH with huge prostate and bladder stones, for which open surgery is usually performed.

\section{CONFLICT OF INTEREST}

No potential conflict of interest relevant to this article was reported.

\section{REFERENCES}

1. Smith RD, Patel A. Transurethral resection of the prostate revisited and updated. Curr Opin Urol 2011;21:36-41.

2. Lee JY, Han JH, Kim TH, Yoo TK, Park SY, Lee SW. Laparoendoscopic single-site ureterolithotomy for upper ureteral stone disease: the first 30 cases in a multicenter study. J Endourol 2011;25:1293-8.

3. Lee SW, Lee JY. Laparoendoscopic single-site urological surgery using a homemade single port device: the first 70 cases performed at a single center by one surgeon. J Endourol 2011;25:257-64.

4. Lee JY, Han JH, Moon HS, Yoo TK, Choi HY, Lee SW. Single-port transvesical enucleation of the prostate for benign prostatic hyperplasia with severe intravesical prostatic protrusion. World J Urol
2011 Sep 9 [Epub]. DOI: 0.1007/s00345-011-0758-0.

5. Desai MM, Fareed K, Berger AK, Astigueta JC, Irwin BH, Aron M, et al. Single-port transvesical enucleation of the prostate: a clinical report of 34 cases. BJU Int 2010;105:1296-300.

6. Oh JJ, Park DS. Novel surgical technique for obstructive benign prostatic hyperplasia: finger-assisted, single-port transvesical enucleation of the prostate. J Endourol 2011;25:459-64.

7. Lee JY, Lee SW. Concomitant laparoendoscopic single-site surgery for ureterolithotomy and contralateral renal cyst marsupialization. Korean J Urol 2011;52:64-7.

8. Desai MM, Aron M, Canes D, Fareed K, Carmona O, Haber GP, et al. Single-port transvesical simple prostatectomy: initial clinical report. Urology 2008;72:960-5.

9. Sotelo RJ, Astigueta JC, Desai MM, Canes D, Carmona O, De Andrade RJ, et al. Laparoendoscopic single-site surgery simple prostatectomy: initial report. Urology 2009;74:626-30.

10. Choi JD, Kim HS, Ju SH, Lee SY, Han DH, Jeong BC. Initial experience with LESS and hybrid LESS in patients with benign urologic disease. Minim Invasive Ther Allied Technol 2011 Feb 18 [Epub]. DOI:10.3109/13645706.2010.543982.

11. Choi KH, Ham WS, Rha KH, Lee JW, Jeon HG, Arkoncel FR, et al. Laparoendoscopic single-site surgeries: a single-center experience of 171 consecutive cases. Korean J Urol 2011;52:31-8.

12. Kaouk JH, Autorino R, Kim FJ, Han DH, Lee SW, Yinghao S, et al. Laparoendoscopic single-site surgery in urology: worldwide multiinstitutional analysis of 1076 cases. Eur Urol 2011;60:998-1005.

13. Autorino R, Cadeddu JA, Desai MM, Gettman M, Gill IS, Kavoussi LR, et al. Laparoendoscopic single-site and natural orifice transluminal endoscopic surgery in urology: a critical analysis of the literature. Eur Urol 2011;59:26-45. 